\title{
Neuropsychiatric Behaviors in the MPTP Marmoset Model of Parkinson's Disease
}

\author{
Susan H. Fox, Naomi Visanji, Gaby Reyes, Philippe Huot, \\ Jordi Gomez-Ramirez, Tom Johnston, Jonathan M. Brotchie
}

\begin{abstract}
Objectives: Neuropsychiatric symptoms are increasingly recognised as a significant problem in patients with Parkinson's disease (PD). These symptoms may be due to 'sensitisation' following repeated levodopa treatment or a direct effect of dopamine on the disease state. The levodopa-treated MPTP-lesioned marmoset was used as a model of neuropsychiatric symptoms in PD patients. Here we compare the time course of levodopa-induced motor fluctuations and neuropsychiatric-like behaviors to determine the relationship between duration of treatment and onset of symptoms. Methods: Marmosets were administered 1-methyl-4-phenyl-1,2,3,6tetrahydropyridine ( $2.0 \mathrm{mg} / \mathrm{kg} \mathrm{s.c.)} \mathrm{for} \mathrm{five} \mathrm{days,} \mathrm{resulting} \mathrm{in} \mathrm{stable} \mathrm{parkinsonism.} \mathrm{Levodopa} \mathrm{(15} \mathrm{mg/kg} \mathrm{and} \mathrm{benserazide,} 3.75 \mathrm{mg} / \mathrm{kg}$ ) p.o.b.i.d. was administered for 30 days. Animals were evaluated for parkinsonian disability, dyskinesia and on-time (motor fluctuations) and neuropsychiatric-like behaviors on Day 0 (prior to levodopa) and on Days 1, 7, 13, 27 and 30 of treatment using post hoc DVD analysis by a trained rater, blind to the treatment day. Results: The neuropsychiatric-like behavior rating scale demonstrated high interrater reliability between three trained raters of differing professional backgrounds. As anticipated, animals exhibited a progressive increase in levodopa-induced motor fluctuations, dyskinesia and wearing-off, that correlated with the duration of levodopa therapy. In contrast, levodopa-induced neuropsychiatric-like behaviors were present on Day 1 of levodopa treatment and their severity did not correlate with duration of treatment. Conclusions: The data suggest that neuropsychiatric disorders in PD are more likely an interaction between levodopa and the disease state than a consequence of sensitisation to repeated dopaminergic therapy.
\end{abstract}

RÉSUMÉ: Comportements neuropsychiatriques dans le modèle de la maladie de Parkinson induite par le MPTP chez le ouistiti. Objectifs : Il est de plus en plus accepté que les symptômes neuropsychiatriques constituent un problème important chez les patients atteints de la maladie de Parkinson (MP). Ces symptômes pourraient être dus à une «sensibilisation » suite au traitement par la lévodopa ou à un effet direct de la dopamine sur la maladie. Le ouistiti, qui a subi une lésion par la MPTP et qui a été traité par la lévodopa, a été utilisé comme modèle des symptômes neuropsychiatriques observés chez les patients atteints de la MP. Nous avons comparé l'évolution dans le temps des fluctuations motrices induites par la lévodopa et des comportements d'aspect neuropsychiatrique pour déterminer la relation entre la durée du traitement et le début des symptômes. Méthodes : De la 1-méthyl-4-phényl-1,2,3,6-tétrahydropyridine $(2,0 \mathrm{mg} / \mathrm{kg} \mathrm{s.c.)} \mathrm{a} \mathrm{été} \mathrm{administrée} \mathrm{à} \mathrm{des} \mathrm{ouistitis} \mathrm{pendant} \mathrm{cinq} \mathrm{jours} \mathrm{pour} \mathrm{induire} \mathrm{un}$ parkinsonisme stable. De la lévodopa $(15 \mathrm{mg} / \mathrm{kg})$ et du bensérazide $(3,75 \mathrm{mg} / \mathrm{kg})$ ont été administrés p.o. bid pendant 30 jours. Nous avons évalué l'invalidité parkinsonienne chez les animaux, les dyskinésies et les fluctuations motrices et les comportements d'aspect neuropsychiatrique au jour 0 (avant l'administration de lévodopa) et aux jours 1, 7, 13,27 et 30 du traitement au moyen de l'analyse post hoc de DVD par un évaluateur entraîné, en aveugle quant au jour de traitement. Résultats : L'échelle d'évaluation des comportements d'aspect neuropsychiatrique a démontré une grande fiabilité inter-évaluateur entre trois évaluateurs entraînés possédant une formation professionnelle différente. Tel que prévu, les animaux présentaient une augmentation progressive des fluctuations motrices induites par la lévodopa, des dyskinésie et de l'épuisement de l'effet en fin de dose qui étaient corrélés à la durée du traitement par la lévodopa. Par contre, les comportements d'aspect neuropsychiatrique étaient présents le premier jour du traitement par la lévodopa et leur sévérité n'était pas corrélée à la durée du traitement. Conclusions : Selon nos données, les troubles neuropsychiatriques dans la MP sont vraisemblablement dus à une interaction entre la lévodopa et la maladie et ne sont pas une conséquence de la sensibilisation à l'administration répétée de lévodopa.

Can. J. Neurol. Sci. 2010; 37: 86-95

Behavioral and psychiatric problems are common in advanced idiopathic Parkinson's disease (PD) ${ }^{1,2}$. These symptoms include psychotic problems consisting of illusions, well-formed visual hallucinations, paranoid delusions and hypomania ${ }^{3}$. In addition, a range of maladaptive, repetitive, reward- or motivation-based behaviors are increasingly recognised in patients with $\mathrm{PD}$, following treatment with dopamine-replacement therapy ${ }^{4}$. These symptoms include a range of impulse control disorders including drug addiction,

From the Division of Neurology (SHF), Toronto Western Research Institute (SHF, NV, GR, PH, JGR, TJ, JMB), University of Toronto, Toronto Western Hospital, Toronto, Ontario, Canada.

Received May 11, 2009. Final Revisions Submitted August 24, 2009. Correspondence to: Susan H. Fox, Division of Neurology, Movement Disorders Clinic MCL7-421, Toronto Western Hospital, 399, Bathurst St, Toronto, Ontario, M5V 2S8, Canada. 
pathological gambling, excessive eating, shopping and hypersexuality ${ }^{5-8}$. Patients may also develop repetitive, purposeless, stereotypical behaviors where they undertake various motor activities ranging from excessive time spent in tasks including sorting, tidying, tinkering, that has been termed hobbyism or punding ${ }^{9,10}$. Many of these symptoms will co-exist ${ }^{9}$. All these behaviors are associated with dopamine replacement and may respond to a reduction in dopaminergic medications ${ }^{11,12}$. Other symptoms such as hallucinations, often continue despite a reduction in dopaminergic medication suggesting that they may have non-dopaminergic etiology ${ }^{13}$.

However, the relative contribution of medication per se and disease processes in all these neuropsychiatric problems remains unknown due to multiple confounding factors in clinical studies. Thus, it remains unknown if such behaviors occur as a result of sensitisation to repeated dopaminergic stimulation or are an effect of underlying disease state. In contrast, the development of motor fluctuations in PD, which include reduced duration of action of levodopa called wearing-off, and involuntary movements, dyskinesia, are a well known consequence of repeated levodopa therapy over time ${ }^{14,15}$.

Until recently, there has been no validated preclinical means of investigating the pathophysiology of neuropsychiatric symptoms and the role of dopaminergic drugs in this regard, in PD. We have recently described an animal model of what we termed 'psychosis-like' behaviors in PD in 1-methyl-4-phenyl1,2,3,6-tetrahydropyridine (MPTP)-lesioned marmosets, that have received prior long-term treatment with levodopa ${ }^{16,17}$. These animals experience a pattern of abnormal behaviors consisting of increased speed and persistence of movement above that seen in a normal animal, hyperkinesia; repetitive grooming (which we suggested as plausible expression of compulsive behavior); staring or tracking non-apparent stimuli (which might represent hallucinatory-like behavior), and a range of stereotypies (e.g. pacing, repetitive side-to side jumping and running in circles), that are idiosyncratic and reproducible each time an animal receives levodopa. These behaviors are similar to "psychotic" behaviors previously reported in normal marmosets and macaques in response to stimulants ${ }^{18,19}$. Furthermore, these behaviors are distinct from levodopa-induced dyskinesia which include chorea, (random, flowing limb movements) and dystonia, (more sustained limb and trunk postures) ${ }^{16}$. We have undertaken pharmacological validation of these behaviors in the MPTP-lesioned marmoset model using agents known to decrease or increase neuropsychiatric symptoms in PD patients. Thus, the atypical antipsychotics, clozapine and quetiapine reduced behaviors without affecting parkinsonian disability, whereas haloperidol caused marked worsening of parkinsonian disability; amantadine reduced dyskinesia but increased hallucinatory-like behaviors. Thus the pattern of change in psychotomimetic behaviors demonstrated that the MPTPlesioned marmoset model has predictive validity as a model of the neuropsychiatric symptoms in PD patients ${ }^{16}$.

To address the issue of the relationship between duration of levodopa treatment and development of neuropsychiatric symptoms, we evaluated the time course of development of abnormal behaviors in previously untreated MPTP-lesioned monkeys, after initiating, de novo, a regime of 30 days treatment with levodopa (the duration of treatment typically required to induce stable levodopa-induced dyskinesia in the MPTPlesioned marmoset, as previously described ${ }^{20,21}$.

\section{METHODS}

Marmosets (Callithrix jacchus), $\mathrm{N}=14$ (all female, weight 350-444 g), (Harlan, USA) were used in this study. Animals were housed in groups of 2-3 and used in accordance with approved local institution protocol (UHN 02/053) and the regulations defined by the Canadian Council on Animal Care. Animals are identified by non-toxic, color-coded dye on the hair of the external ear. The animals were kept in controlled housing conditions, with constant temperature $\left(25^{\circ} \mathrm{C}\right)$, relative humidity (50\%) and $12 \mathrm{~h}$ light/dark cycle (08.00 lights on). The animals had free access to food, fresh fruit supplements and water. The housing environment was enriched with auditory and tactile stimuli. Animals were acclimatized to handling and placed into the study observation cages $(0.8 \mathrm{~m} \times 0.8 \mathrm{~m} \times 0.7 \mathrm{~m})$ with a branch, a dish of fruit and a water bottle, for two hours every one to two days over a two week period. The observation cages were located in a separate room from the home cages. The marmosets were placed singly into the observation cages; they were unable to see each other but could hear each other.

Seven animals were administered MPTP hydrochloride (2.0 $\mathrm{mg} / \mathrm{kg}$ s.c. for five consecutive days) (Sigma, USA). This treatment results in a stable parkinsonian syndrome, characterised by bradykinesia, hunched posture and a reduced range of movement, as previously described ${ }^{22,21}$. Following MPTP administration, the animals were allowed to recover for 12 weeks to allow parkinsonian symptoms to stabilise. Animals were then treated with levodopa as Prolopa ${ }^{\circledR}$ p.o. via gavage (equivalent to $15 \mathrm{mg} / \mathrm{kg}$ levodopa and $3.75 \mathrm{mg} / \mathrm{kg}$ benserazide dissolved in fruit juice) (Hoffman-La Roche, Canada) twicedaily with levodopa for 30 days. This dose has been used previously in the MPTP-marmoset to reverse parkinsonism and induce dyskinesia ${ }^{16}$. On Day 0 (before start of levodopa treatment) and on Days 1, 7, 13, 27 and 30 of the levodopa treatment course, animals' behavior was assessed following the morning dosing of levodopa. On each of these test days, animals had no morning feed to ensure no interference with absorption of oral levodopa and were fed following completion of the behavioral testing. In all cases, animals were administered levodopa, immediately placed singly into the observation cages and behavior recorded for a period of four hours, using a digital video camera connected to a DVD recorder for post-hoc analysis. Animals were left undisturbed during this period.

The remaining seven animals were used to assess the behavioral effects of a single dose of levodopa in non parkinsonian, normal animals. Each animal received a single dose of levodopa as Prolopa ${ }^{\circledR}$ p.o. (equivalent to $15 \mathrm{mg} / \mathrm{kg}$ levodopa and $3.75 \mathrm{mg} / \mathrm{kg}$ benserazide), administered by gavage. This is a standard dose of levodopa used in the non-human primate to ensure full reversal of parkinsonian disability. Commencing immediately after levodopa administration, animals were placed into the cage and behavior recorded as described above.

A trained observer, blind to the day of levodopa treatment, scored behaviors in ten minute time intervals using DVD recordings for four hours; the 'peak dose', 40 - 120 minutes post levodopa, (the time of maximal reversal of parkinsonian 
disability) was also calculated. Assessments were made to determine:

a) The effect of levodopa on reversal of parkinsonian motor disability using a standard rating scale ${ }^{16,21}$ that is a composite score of range of movement, bradykinesia, posture, and attention; the higher the score, the greater the disability (maximum score/10 mins $=36$ ).

b) The motor complications of long-term levodopa i.e. dyskinesia (chorea and dystonia) and wearing-off (reduced duration of action or 'on-time' of levodopa dose). Levodopainduced dyskinesia disability was scored using a rating scale from $0=$ absent, $1=$ mild to $4=$ severe, $($ score $0-4)$. Chorea and dystonia were rated separately and added to give a total dyskinesia score, (maximum score/ $10 \mathrm{~min}=8$ ). The duration of action of levodopa in alleviating parkinsonian disability (i.e. 'on time') was defined as the time during which animals had a bradykinesia score of zero and was expressed in minutes.

c) Neuropsychiatric-like behaviors were rated during the same time periods, using a revised MPTP-lesioned marmoset neuropsychiatric behavior rating scale (adapted from ${ }^{16}$ (Table 1). Four categories of behavior (hyperkinesia; repetitive grooming; response to non-apparent stimuli and stereotypies were rated separately using a 5 point disability rating scale, for the same ten minute time period in which parkinsonian disability and dyskinesia were rated to allow comparison between these ratings. Scores were cumulated for each time period to give a total neuropsychiatric-like behavior score (maximum total score /10 min = 16). Reliability of the scale was assessed using three trained raters (SF, GR, $\mathrm{PH}$ ); each evaluated the animals on 1 test day, over the peak dose period, blind to treatment day.

\section{Statistical analysis}

Data for parkinsonian disability, dyskinesia and neuropsychiatric-like behaviors for the time points representing peak effect (40 - 120 min post levodopa) were expressed as median peak dose score (+ range) and analysed using nonparametric, one way analysis of variance (ANOVA), (Friedman) and post hoc analysis using Dunn's Multiple Comparison Test. The behavioral effects of levodopa in normal animals, compared to MPTP-treated animals (levodopa dosing on Day 1) were analysed using Mann Whitney $U$ test. For duration of on-time analysis, data were expressed as mean (+ s.e.m.) and analysed using a parametric repeated measures ANOVA followed by Bonferroni's Multiple Comparison Test. Linear regression was performed to investigate the relationship between dyskinesia, total neuropsychiatric-like behaviors, subtypes of neuropsychiatric-like behaviors and duration of levodopa treatment. Spearman's correlation analysis was performed on scores from the three separate raters. Significance was set at $\mathrm{P}<$ 0.05 in all cases. Analyses were conducted with GraphPad Prism® (version 4.0).

\section{RESULTS}

\section{Levodopa-induced reversal of parkinsonian disability}

Levodopa treatment had a significant effect on peak dose parkinsonian disability (Friedman test FS $=16.40_{(5,36)}, \mathrm{P}<0.01$, $\mathrm{n}=7$ ). Peak dose parkinsonian disability was significantly reversed on the first day of treatment, Day 1, compared to Day 0, and with repeated daily levodopa, there was a sustained improvement in peak dose parkinsonian disability following levodopa therapy, on Days 7, 13, 27 and 30; although the change

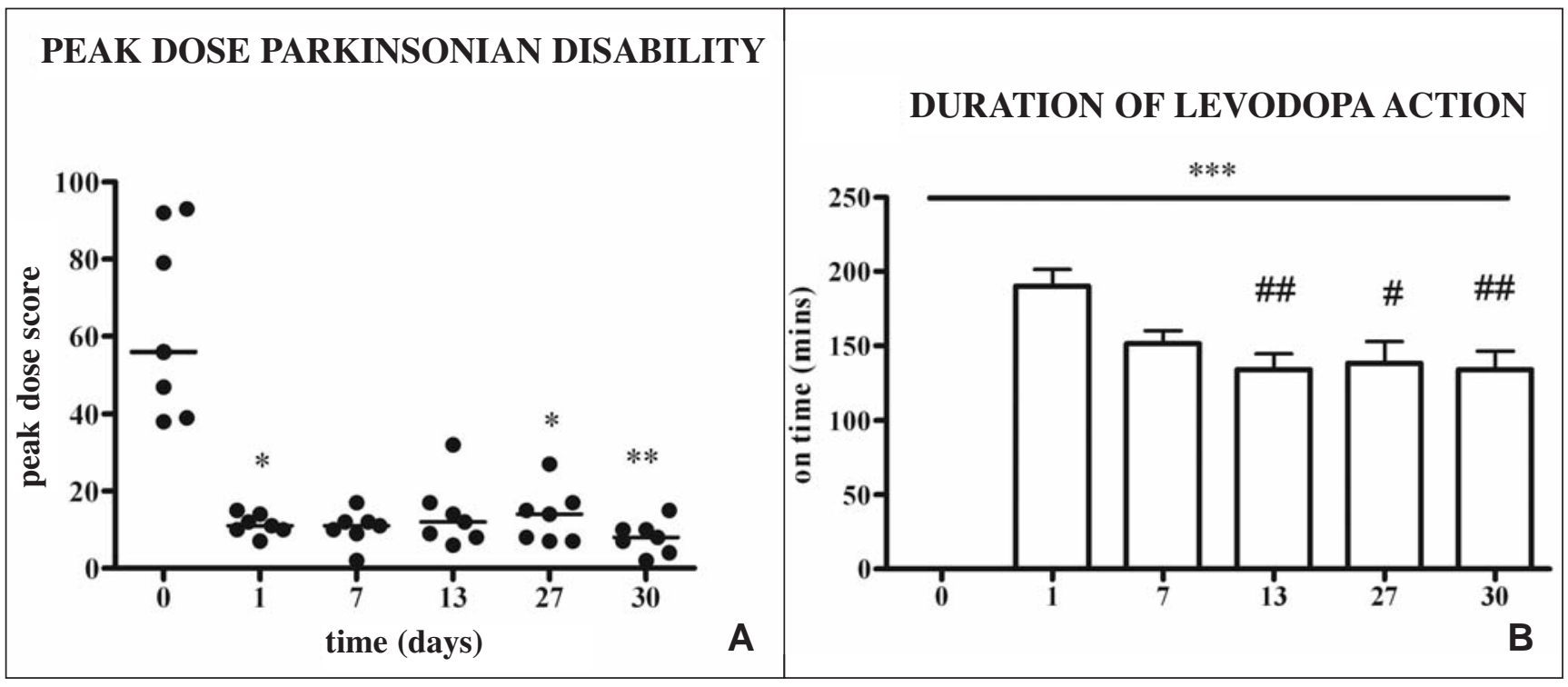

Figure 1: A) Effect of daily levodopa therapy on peak dose parkinsonian disability in the MPTP-lesioned marmoset. Data represent individual animals, bar is median score of accumulated parkinsonian disability scores at peak dose, $* P<0.05, * * P<0.01$ compared to Day 0 . B) Effect of daily levodopa therapy on duration of 'on-time', in the MPTP-lesioned marmoset. Data represent mean ( + s.e.m.) mins of reversal of parkinsonian disability scores post levodopa, ***P $<0.001$, compared to Day 0; \#P $<0.05$, \#\# < 0.01 compared to Day 1. 
Table 1: MPTP-lesioned marmoset neuropsychiatric-like behavior rating scale

\begin{tabular}{|c|c|}
\hline Category of behavior & Level of disability \\
\hline $\begin{array}{l}\text { 1. Hyperkinesia } \\
\text { Locomotor activity consisting of running, jumping or climbing, that is } \\
\text { faster than normal and/or inability of animal to remain in one position } \\
\text { for }>5 \text { secs without exhibiting locomotion. }\end{array}$ & $\begin{array}{l}0=\text { Normal. Normal speed and/or able to remain in one position for }>5 \\
\text { secs. } \\
1=\text { Mild. Present }<30 \% \text { of time and animal is still able to eat, drink and } \\
\text { perform normal activity. } \\
2=\text { Moderate. Present }>30 \% \text { of time and animal is still able to eat, drink } \\
\text { and perform normal activity. } \\
3=\text { Marked. Present }<30 \% \text { of time; animal is unable to eat, drink and } \\
\text { perform normal activity. } \\
4=\text { Severe. Present }>30 \% \text { of time and animal is unable to eat, drink and } \\
\text { perform normal activity. }\end{array}$ \\
\hline $\begin{array}{l}\text { 2. Response to non-apparent stimuli - } \\
\text { Tracking behavior: head movements following non-apparent stimuli (> } \\
10 \text { seconds/min) and/or } \\
\text { Staring behavior: head still, looking in one direction at non-apparent } \\
\text { stimulus for extended period ( }>10 \text { seconds/min) }\end{array}$ & $\begin{array}{l}0=\text { Normal. No responses to non-apparent stimuli. } \\
1=\text { Mild } \text {. Present }<30 \% \text { of time and animal is still able to eat, drink and } \\
\text { perform normal activity. } \\
2=\text { Moderate. Present }>30 \% \text { of time and animal is still able to eat, drink } \\
\text { and perform normal activity. } \\
3=\text { Marked } \text { Present }<30 \% \text { of time; animal is unable to eat, drink and } \\
\text { perform normal activity. } \\
4=\text { Severe. Present }>30 \% \text { of time and animal is unable to eat, drink and } \\
\text { perform normal activity. } \\
\text { (Instructions; give one score only; if more than one type of response to non- } \\
\text { apparent stimuli, record score for most disabling). }\end{array}$ \\
\hline $\begin{array}{l}\text { 3. Repetitive grooming } \\
\text { Grooming or scratching repetitively ( }>5 \text { times } / \mathrm{min} \text { ) }\end{array}$ & $\begin{array}{l}0=\text { Normal. Scratches } / \text { grooming }<5 \text { times } / \mathrm{min} \text {. } \\
1=\text { Mild } \text {. Present }<30 \% \text { of time and animal is still able to eat, drink and } \\
\text { perform normal activity. } \\
2=\text { Moderate. Present }>30 \% \text { of time and animal is still able to eat, drink } \\
\text { and perform normal activity. } \\
3=\text { Marked. Present }<30 \% \text { of time; animal is unable to eat, drink and } \\
\text { perform normal activity. } \\
4=\text { Severe. Present }>30 \% \text { of time and animal is unable to eat, drink and } \\
\text { perform normal activity. }\end{array}$ \\
\hline $\begin{array}{l}\text { 4. Stereotypies } \\
\text { a) Side-to-side repetitive whole body jumping movements on floor of } \\
\text { cage }(>2 \text { times/min) } \\
\text { b) Head checking movements that are repetitive, quick, side-to-side, } \\
\text { exaggerated large amplitude, often with associated body movements ( }> \\
3 \text { times } / \text { min) } \\
\text { c) Circling behavior - whole body turning in circles on floor or cage ( }> \\
2 \text { times } / \mathrm{min}) \\
\text { d) Fiddling with and/or repetitively grasping at cage bars with forearms } \\
(>2 \text { times/min) }\end{array}$ & $\begin{array}{l}0=\text { Normal. No stereotypies present. } \\
1=\text { Mild } \text {. Present }<30 \% \text { of time and animal is still able to eat, drink and } \\
\text { perform normal movement in between. } \\
2=\text { Moderate. Present }>30 \% \text { of time and animal is still able to eat, drink } \\
\text { and perform normal movement in between. } \\
3=\text { Marked } \text {. Present }<30 \% \text { of time; animal is unable to eat, drink and } \\
\text { perform normal movements in between. } \\
4=\text { Severe. Present }>30 \% \text { of time and animal is unable to eat, drink and } \\
\text { perform normal movement in between. } \\
\text { (Instructions; give one score only; if more than one type of stereotypy, } \\
\text { record score for most disabling). }\end{array}$ \\
\hline
\end{tabular}

was significant compared to Day 0 only on Days 27 and 30 (Dunn's multiple comparison tests, $\mathrm{P}<0.05, \mathrm{P}<0.01, \mathrm{n}=7$ respectively) (Figure 1A). There was no significant difference between peak dose parkinsonian disability on Days 1, 7, 13, 27 and 30 .

\section{Duration of action of levodopa}

Daily levodopa treatment resulted in a progressive reduction in duration of action of levodopa, ie wearing-off (Repeated Measures ANOVA, followed by Bonferroni's Multiple Comparison test FS = 43.68 $5,36, \mathrm{P}<0.001, \mathrm{n}=7$ ) (Figure 1B). On Day 1, levodopa reversed parkinsonian disability for mean (+ s.e.m.) $190(+11.3)$ minutes $(\mathrm{min})$ compared to only $134.4(+$
14.21) min on Day 13 and $134.3(+12.1)$ min on day 30 of levodopa therapy ( $\mathrm{P}<0.001, \mathrm{n}=7$, compared to Day 1 , for both days) (Figure 1B).

\section{Levodopa-induced dyskinesia}

Levodopa treatment had a significant effect on peak dose dyskinesia (Friedman test, FS $=21.31_{5,36}, \mathrm{P}<0.001, \mathrm{n}=7$ ) (Figure 2A). Dyskinesia was present on the first day of levodopa therapy (Day 1) in six out of seven animals, but only at a low and non-significant level. The dyskinesia present on D ay 1 was choreic in all animals (Figure 2B). Repeated daily treatment with levodopa resulted in an increase in dyskinesia compared to Day 0 (Dunn's multiple comparison tests, $\mathrm{P}<0.05, \mathrm{P}<0.01, \mathrm{P}<0.01$ respectively) (Figure 2A). Peak dose dyskinesia on Days 7, 13, 


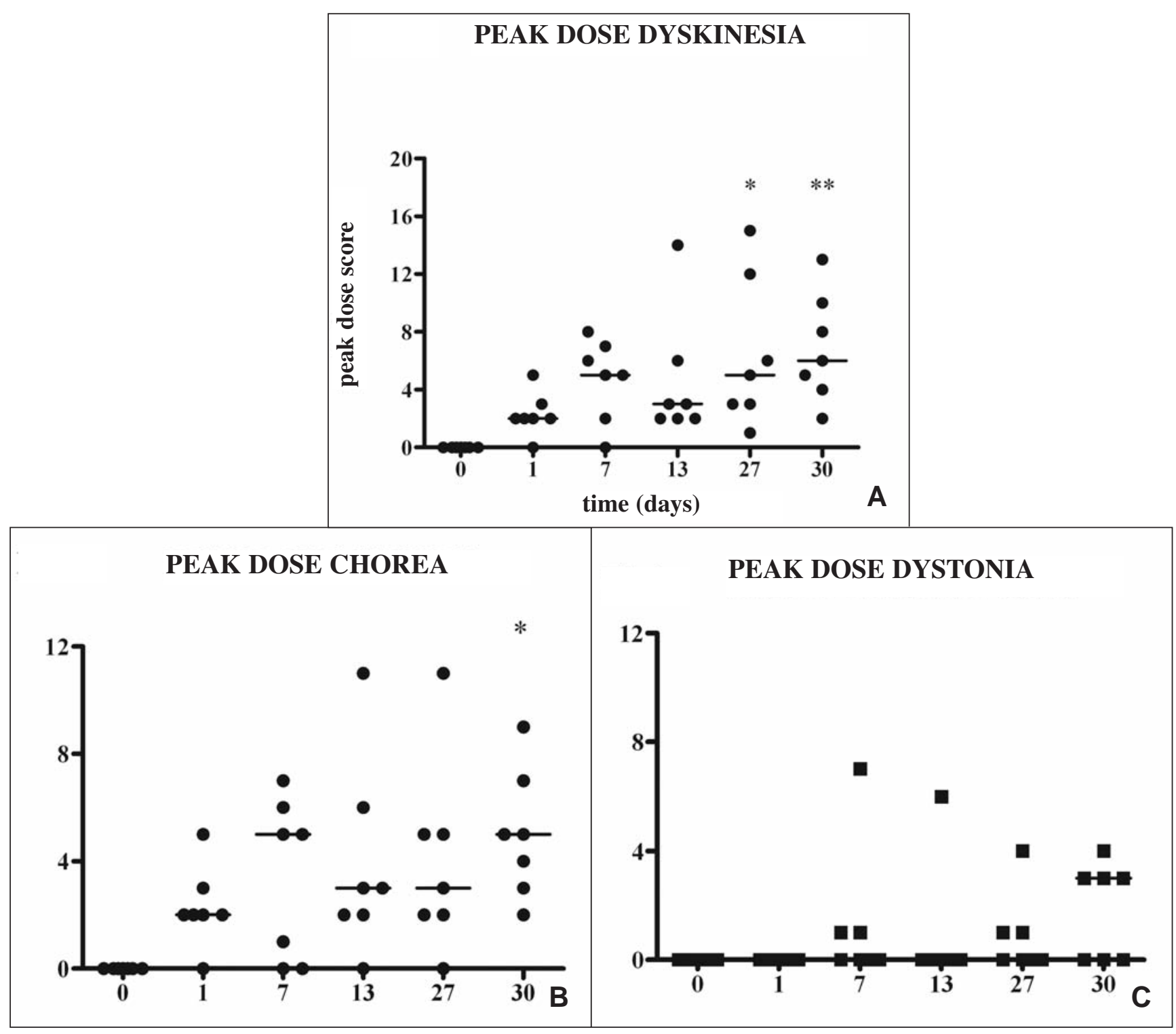

Figure 2: Effect of daily levodopa therapy on peak dose dyskinesia in the MPTP-lesioned marmoset. Figure A shows total peak dose dyskinesia, data represent individual animals, bar is median score of accumulated dyskinesia scores at peak dose $* P<0.05$, **P<0.01 compared to Day 0 . Figure B shows chorea and Figure $C$ dystonia on each treatment day, $* P<0.05$, for chorea scores compared to Day 0.

27 and 30 consisted of a mixture of chorea and dystonia in all animals (Figure 2B, 2C). Peak dose chorea was significantly increased on Day 30 compared to Day 0 (Friedman test followed by Dunn's multiple comparison tests, $\left.\mathrm{F}=14.00_{(5,36)}, \mathrm{P}<0.05\right)$ (Figure 2B). There was no significant difference in peak dose dystonia between treatment days (Figure 2C). Linear regression analysis showed a significant positive association between peak dose dyskinesia and days of levodopa treatment $\left(r^{2}=0.2545\right.$, $\left.\mathrm{F}=5.461_{(1,16)}, \mathrm{P}<0.05\right)$.

\section{Levodopa-induced neuropsychiatric-like behaviors}

There was correlation between three independent raters on total and subscores of the neuropsychiatric-like behavior rating scale (Table 2). Levodopa therapy had a significant effect on total peak dose neuropsychiatric-like behavior (Friedman test, $\mathrm{FS}=18.48_{(5,36)}, \mathrm{P}<0.01, \mathrm{n}=7$ ) (Figure 3). Neuropsychiatric-like behaviors were absent on Day 0 in all animals and present on the first day of levodopa therapy in six out of seven animals (Dunn's multiple comparison tests, $\mathrm{P}<0.01$ ) (Figure 3 ). With repeated levodopa treatment, neuropsychiatric-like behaviors were present in all animals, on all days and there was no significant difference between treatment Day 1 compared to Days 7, 13, 27 and 30 (Dunn's multiple comparison test, all P>0.05) (Figure 3). Peak dose score on Days 1 and 30 was significantly greater than on Day 0 (Dunn's multiple comparison tests, $\mathrm{P}<0.01$ ). Linear regression demonstrated no significant correlation between 
Table 2: Inter-rater reliability (Spearman correlation coefficients) of neuropsychiatric-like behavior rating scale

\begin{tabular}{l|l|l|l|l|l}
\hline $\begin{array}{l}\text { Rater } \\
\text { comparison }\end{array}$ & Total score & $\begin{array}{l}\text { Hyperkinesia } \\
\text { subscores }\end{array}$ & $\begin{array}{l}\text { Repetitive grooming } \\
\text { subscores }\end{array}$ & $\begin{array}{l}\text { Response to non-apparent } \\
\text { stimuli subscores }\end{array}$ & $\begin{array}{l}\text { Stereotypies } \\
\text { subscores }\end{array}$ \\
\hline $\begin{array}{l}\text { Rater 1 vs } \\
\text { Rater 2 }\end{array}$ & $0.972 * * *$ & $0.885^{*}$ & $0.78^{*}$ & $0.933^{* *}$ & $0.889 *$ \\
\hline $\begin{array}{l}\text { Rater 1 vs } \\
\text { Rater 3 }\end{array}$ & $0.937 * * *$ & $0.795^{*}$ & $0.97 * * *$ & $0.913 * *$ & $0.843^{*}$ \\
\hline $\begin{array}{l}\text { Rater 2 vs } \\
\text { Rater 3 }\end{array}$ & $0.964 * * *$ & $0.770 *$ & $0.78^{*}$ & $0.914 * *$ & $0.769 *$ \\
\hline
\end{tabular}

$* \mathrm{P}<0.05, * * \mathrm{P}<0.01, * * * \mathrm{P}<0.0001$

neuropsychiatric-like behavior and duration of levodopa treatment $\left(\mathrm{r}^{2}=0.006, \mathrm{~F}=0.0911_{(1,16)}, \mathrm{P}>0.05\right)$.

The neuropsychiatric-like behavior on Day 1 was predominantly due to hyperkinesia and repetitive grooming. Levodopa treatment has a significant effect on hyperkinesia (Friedman test, FS = 19.21 ${ }_{(5,36)}, \mathrm{P}<0.01, \mathrm{n}=7$ ) (Figure 4A); the highest scores were on Day 1; median 3 (range $0-4$ ), but there was no significant difference compared to Day 0 or any other treatment day (Dunn's multiple comparison test, $\mathrm{P}>0.05$, for all days). Repetitive grooming was present in five animals on Day 1 but only two animals on Day 30 and there was no significant difference between treatment days (Friedman test, followed by Dunn's Multiple Comparison Test, $\mathrm{P}>0.05$ ) (Figure 4B). Levodopa therapy had a significant effect on responses to nonapparent stimuli (Friedman test, $\mathrm{F}=14.45_{(5,36)}, \mathrm{P}<0.05, \mathrm{n}=7$ ). The highest score for response to non-apparent stimuli were seen

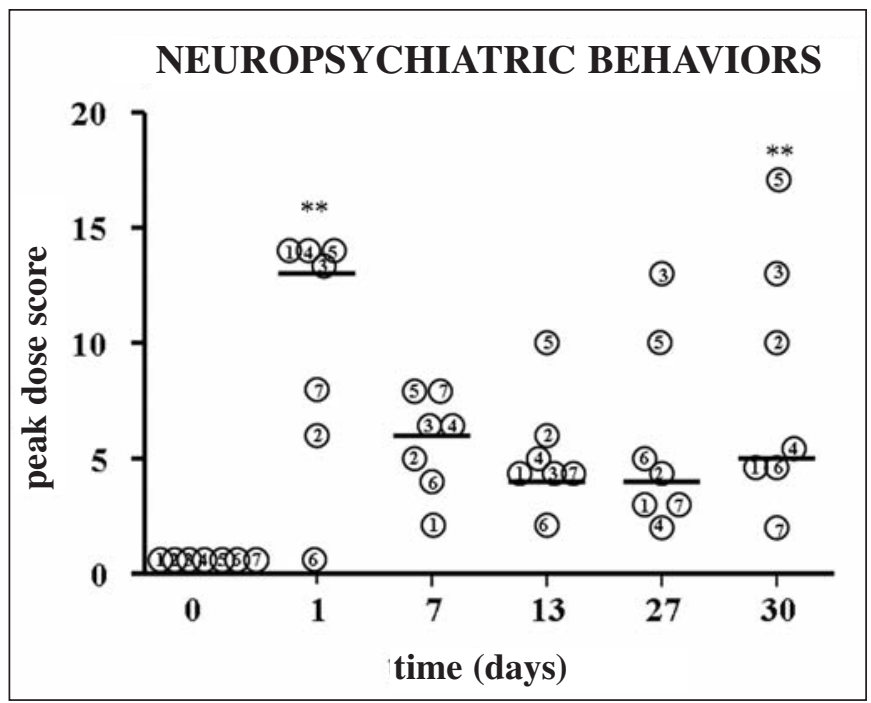

Figure 3: Effect of daily levodopa therapy on peak dose neuropsychiatric-like behavior in the MPTP-lesioned marmoset. Data represent individual animals (numbered $1-7$ ); bar is median score of accumulated neuropsychiatric-like behavior scores at peak dose, ${ }^{* * P}<$ 0.01 , compared to Day 0. on Days 13, 27 and 30 (Dunn's Multiple Comparison test , $\mathrm{P}<$ 0.05, Day 0 compared to Day 13 and Day 30) (Figure 4C).

The most commonly encountered subtype of neuropsychiatriclike behavior was stereotypy. There was a significant effect of levodopa therapy on development of these behaviors (Friedman test $\mathrm{F}=12.05_{(5,36)}, \mathrm{P}<0.05, \mathrm{n}=7$ ) (Figure 4D). Stereotypies were present on Day 1 in six out of seven animals and following repeated treatment with levodopa, median stereotypy scores were stable, with no significant difference between treatment days (Dunn's multiple comparison test, all comparisons $\mathrm{P}<$ $0.05)$. Stereotypies, where present, remained animal specific. Using linear regression analysis, there was no significant association between any peak dose behavior sub-score and duration of levodopa treatment $(\mathrm{P}>0.05$ for all subtypes of neuropsychiatric-like behaviors)

In contrast to MPTP-lesioned animals, following a single dose of levodopa, normal (non-parkinsonian) marmosets animals exhibited a normal range of movement, with no effect on bradykinesia, attention or posture; median peak dose range of movement subscores 0 (range $0-3)(n=7)$. There was no levodopa-induced dyskinesia. Two out of seven animals exhibited mild hyperkinetic running around the cage, however no other neuropsychiatric-like behaviors were present. Median peak dose neuropsychiatric-like behavior in normal animals was 0 (range $0-1$ ) compared to 13 (range $0-14$ ) in MPTP-lesioned animals (Day 1) $(\mathrm{P}<0.05$, Wilcoxon signed rank test, $\mathrm{n}=7)$.

\section{Discussion}

Daily levodopa therapy in previously drug-naïve, MPTPlesioned primates resulted in the progressive development of dyskinesia and wearing-off, consistent with previous reports ${ }^{20}$. Animals also exhibited neuropsychiatric-like behaviors, present from the first day of treatment and without any significant association with duration of levodopa therapy. The pathophysiology underlying development of motor fluctuations and neuropsychiatric symptoms in PD may be different.

\section{Methodological issues}

The MPTP-lesioned marmoset model of PD clearly cannot model the subjective nature of many neuropsychiatric symptoms such as agitation, obsessive or delusional thoughts. However, the abnormal levodopa-induced complex behaviors may represent a 


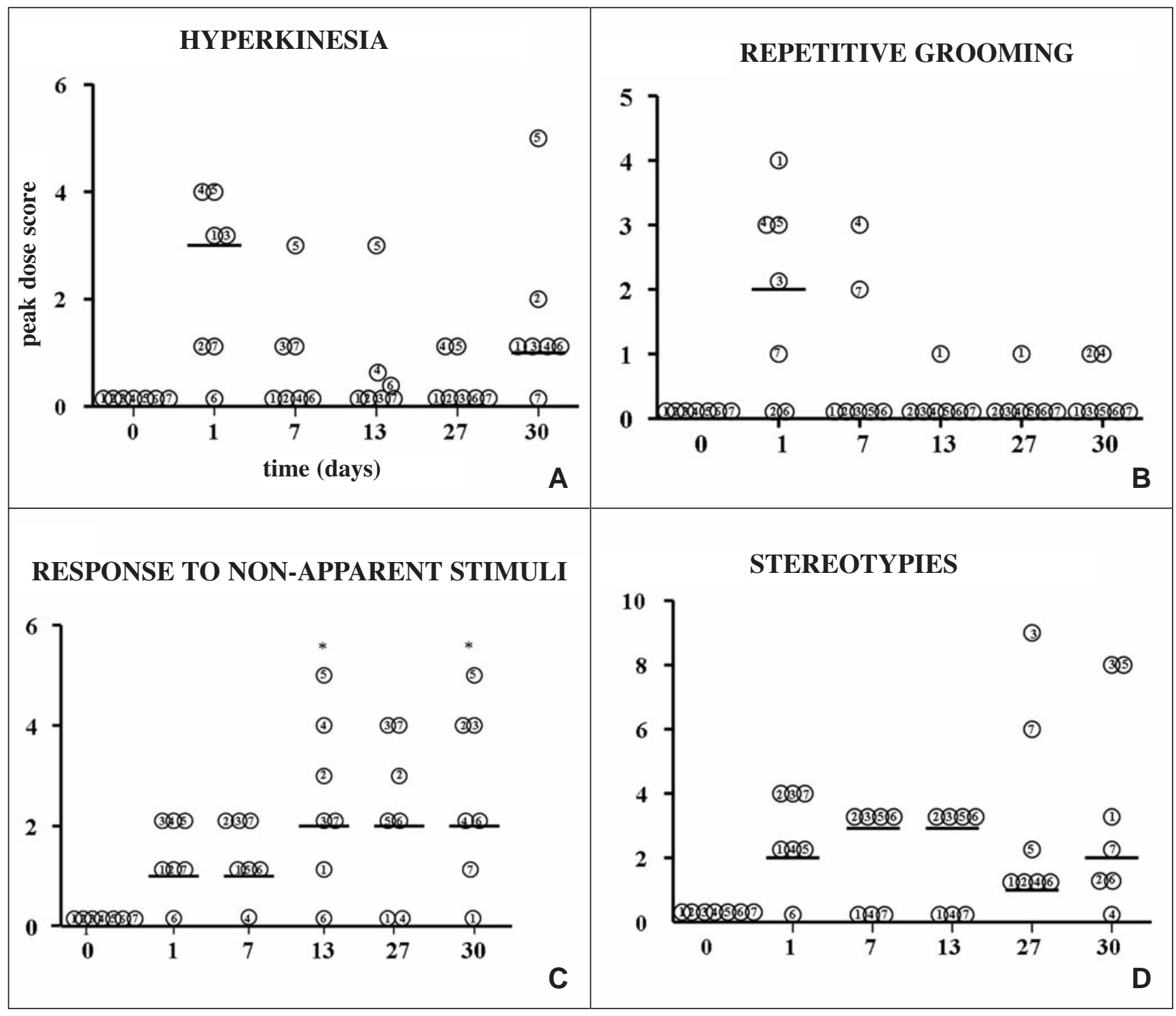

Figure 4: Effect of daily levodopa therapy on subtypes of neuropsychiatric-like behavior in the MPTP-lesioned marmoset. Data represent individual animals (numbered $1-7$ ), bar is median score of accumulated neuropsychiatric-like behavior subscores at peak dose $* P<0.05$, compared to Day 0.

motor equivalent expression of neuropsychiatric symptoms in these animals. We thus propose that the behaviors such as repetitive grooming and responses to non-apparent stimuli may be an expression of compulsive or hallucinatory like symptoms, respectively. To date, no preclinical models of neuropsychiatric behaviors in PD exist to allow investigation of such problems and we propose that this model may be one step towards this. Indeed, the ability of potential new drugs to reverse parkinsonian disability or reduce dyskinesia may be compromised by neuropsychiatric symptoms that do not become apparent until clinical studies; as such the preclinical MPTP-primate model is a useful way of screening for such potential complications. Thus an ideal drug would improve MPTP-induced parkinsonian disability to levels of activity seen in a normal animal, not the abnormal psychotomimetic levels seen with levodopa.

Here we demonstrate that the scale employed to assess neuropsychiatric-like behaviors is sensitive to drug-induced changes and after training shows high levels of inter-rater reproducibility, even if raters have different professional backgrounds. While this scale can be used to assess severity and intensity of neuropsychiatric-like behaviors, we appreciate that it assesses only a subset of all behaviors and especially in primate models of PD, should be incorporated into a battery of nonparametric assessments such as parkinsonism and dyskinesia. An understanding of this broad range of behaviors may be necessary to explain behavior assessed by additional parametric measures 
such as total activity counts using infrared counters, which would affect all behaviors combined.

The dose of levodopa is high in comparison to doses used in PD patients on a mg per $\mathrm{kg}$ basis, however this is to give comparable blood levels of levodopa due to different rates of metabolism of levodopa between primates and humans. Thus the high doses employed are standard in primate studies to ensure full reversal of parkinsonian disability ${ }^{20}$.

\section{Time course of the development of levodopa-induced motor fluctuations}

Six out of the seven animals exhibited dyskinesia on the first dose of levodopa, although at a much lower level than following the 30 day levodopa treatment period. This early and rapid development of levodopa-induced dyskinesia is likely due to the severe (> 90\%) loss of striatal dopamine following MPTP. Dyskinesia was not apparent in normal animals following a single dose of levodopa. With repeated daily treatment, animals developed a progressive increase in severity of peak dose levodopa-induced dyskinesia as we, and others, have previously shown ${ }^{20,23}$. This coincided with a progressive shortening of the duration of reversal of parkinsonism i.e. wearing-off. This development of both dyskinesia and wearing-off is due to repeated levodopa therapy as, once established, there is no further progression of parkinsonian disability in the MPTPlesioned primate.

\section{Time course of the development of levodopa-induced neuropsychiatric-like behaviors}

In contrast to the progressive development of levodopainduced dyskinesia and wearing-off with repeated treatment, neuropsychiatric-like behaviors were present on the first day of treatment and were not correlated with the duration of levodopa treatment. Overall, the early emergence of neuropsychiatric-like behaviors may result from levodopa therapy per se combined with the underlying pathology of MPTP-induced parkinsonism. This is also suggested by the finding that in normal, non parkinsonian, marmosets, following a single dose of levodopa the level of neuropsychiatric-like behavior was very low compared to that seen in parkinsonian monkeys on first administration, and was not characterised by any stereotypies, repetitive grooming or response to non-apparent stimuli behaviors.

The abnormal behaviors observed in the MPTP-lesioned primate may encompass a range of neuropsychiatric problems seem in PD patients, which probably have different pathophysiology, although all are probably related to use of dopaminergic drugs (as none are seen in untreated animals) combined with the underlying pathology of nigrostriatal dopamine loss. Hyperkinesia was most marked on Day 1 and comprised fast, driven, repetitive running and jumping around the cage. The finding that hyperkinesia is at the highest level on Day 1 and does not increase with repeated levodopa therapy, demonstrates that this behavior is separate from dyskinesia. Likewise, the "compulsive" repetitive grooming was also highest on Day 1 compared to subsequent treatment days. Excessive grooming and scratching is unlikely to be simply a reaction to the drug administration as levodopa was given orally. The apparent (but non-significant) higher levels of hyperkinesias and grooming on Day 1 compared to subsequent Days 7, 13 and 27 may also suggest that some of these behaviors are due to anxiety (i.e. fear due to a new environment), although all animals were acclimatised to the cages and handling.

In contrast, stereotypies and the "hallucinatory-like", responses to non-apparent stimuli, were present throughout the levodopa treatment period. Stereotypies remained stable throughout the treatment period, although without any significant association with duration of levodopa treatment, suggesting an effect of the underlying pathology, as none were seen in normal animals. Stereotypies are the most common neuropsychiatric behavior seen in MPTP-lesioned marmosets and are clearly distinct from dyskinesia in that the behavior is a complex, whole body activity e.g. running round in circles in contrast to involuntary movement of the limbs and trunk in dyskinesia. In contrast, the hallucinatory-like behaviors did appear to increase over treatment with higher levels on Days 13 and 30 , suggesting a possible effect of levodopa priming on this subtype of behavior.

\section{Behavioral sensitisation}

In the psychiatry literature, the concept of repetitive treatment with dopaminergic drugs or psychostimulants inducing an increase in behaviors particularly stereotypies, but also psychotic behavior including hallucinatory-like behavior, over time is termed 'behavioral sensitisation' ${ }^{24,25}$. However, this is essentially the same concept as repeated levodopa treatment inducing motor fluctuations in PD patients which has been termed 'priming' in the neurology literature ${ }^{26}$. The mechanisms underlying both behavioral sensitisation and priming probably involve plasticity in basal ganglia circuits, involving the dopaminergic inputs to the striatum, resulting in procedural or habit learning ${ }^{27-29}$. Thus, stereotypies seen in non-parkinsonian animals and people following repeated treatment with amphetamine or cocaine are thought due to an effect of dopamine stimulation within the ventral striatum/nucleus accumbens ${ }^{30,31}$. Of interest, a recent study in PD patients with dopamine dysregulation syndrome, a probable correlate of some of the behaviors observed here, demonstrated enhanced levodopa-induced ventral striatal dopamine release that related to heightened psychomotor activation, suggesting sensitisation of ventral striatum ${ }^{32}$. In both behavioral sensitisation and the development of motor complications, there is increased glutamate transmission, both NMDA and AMPA receptor-mediated within the striatum ${ }^{33-35}$, as well as evidence of enhanced transmission in opioid (dynorphin) neurons in both ${ }^{36-38}$.

However, despite the above mentioned similarities, the basal ganglia circuitry involved in the processes of development of levodopa-induced motor complications and behavioral sensitisation are probably different, thus accounting for the difference in development of these behaviors following chronic levodopa therapy. The pathways involved in dyskinesia involve the substantia nigra pars compacta projections to the motor striatum including lateral putamen, the subthalamic nucleus and internal globus pallidus, the 'motor circuit'39,40. The circuits involving ventral tegmental area projections to ventral striatum, including nucleus accumbens, ventral pallidum and prefrontal cortex are probably involved in behavioral sensitisation; termed the 'motive circuit' 33,41 . 
This topographical arrangement may account for the finding that repeated levodopa therapy was significantly associated with the development of dyskinesia but not neuropsychiatric-like behaviour in the MPTP-lesioned primate. In parkinsonism, the underlying loss of nigrostriatal dopamine permits or supports, the induction of some neuropsychiatric-like behaviors following the first exposure to levodopa, because they involve circuitry that are already in a state similar to behavioral sensitisation in normal animals. Thus neuropsychiatric-like behaviors may occur on initial treatment because of the presence of changes in dopamine receptor sensitivity or other non dopaminergic systems, as a consequence of the nigrostriatal lesion $p e r s e^{42}$. In conclusion, the data suggest that neuropsychiatric disorders in PD are more likely an interaction between dopaminergic drugs and the disease state, than a consequence of sensitisation to repetitive treatment, in contrast to the development of motor fluctuations. Thus identifying PD patients at risk of developing these disorders is essential as symptoms present early in the treatment period and are not due to chronic dopaminergic therapy.

\section{ACKNOWLEDGMENTS}

The authors thank the Parkinson Society Canada (to SHF), The Safra Foundation Fellowship (to JGR, PH), the Krembil Neuroscience Fund and the Cure Parkinson's Trust for financial support.

\section{REFERENCES}

1. Schrag A. Psychiatric aspects of Parkinson's disease--an update. J Neurol. 2004;251(7):795-804.

2. Weintraub D, Stern MB. Psychiatric complications in Parkinson disease. Am J Geriatr. Psychiatry. 2005;13(10):844-51.

3. Ravina B, Marder K, Fernandez HH, Friedman JH, McDonald W, Murphy D, et al. Diagnostic criteria for psychosis in Parkinson's disease: report of an NINDS, NIMH work group. Mov Disord. 2007;22(8):1061-8.

4. Voon V, Fox SH. Medication-related impulse control and repetitive behaviors in Parkinson disease. Arch Neurol. 2007;64(8): 1089-96.

5. Lawrence AD, Evans AH, Lees AJ. Compulsive use of dopamine replacement therapy in Parkinson's disease: reward systems gone awry? Lancet Neurol. 2003;2(10):595-604.

6. Dodd ML, Klos KJ, Bower JH, Geda YE, Josephs KA, Ahlskog JE. Pathological gambling caused by drugs used to treat Parkinson disease. Arch Neurol. 2005;62(9):1377-81.

7. Nirenberg MJ, Waters C. Compulsive eating and weight gain related to dopamine agonist use. Mov Disord. 2006;21(4):524-9.

8. Gallagher DA, O'Sullivan SS, Evans AH, Lees AJ, Schrag A. Pathological gambling in Parkinson's disease: risk factors and differences from dopamine dysregulation. An analysis of published case series. Mov Disord. 2007;22(12):1757-63.

9. Evans AH, Katzenschlager R, Paviour D, O'Sullivan JD, Appel S, Lawrence AD, et al. Punding in Parkinson's disease: its relation to the dopamine dysregulation syndrome. Mov Disord. 2004;19 (4):397-405.

10. Kurlan R. Disabling repetitive behaviors in Parkinson's disease. Mov Disord. 2004;19(4):433-7.

11. Galpern WR, Stacy M. Management of impulse control disorders in Parkinson's disease. Curr Treat Options Neurol. 2007;9(3): 189-97.

12. Kimber TE, Thompson PD, Kiley MA. Resolution of dopamine dysregulation syndrome following cessation of dopamine agonist therapy in Parkinson's disease. J Clin Neurosci. 2008;15 (2):205-8

13. Factor SA, Feustel PJ, Friedman JH, Comella CL, Goetz CG, Kurlan R, et al. Longitudinal outcome of Parkinson's disease patients with psychosis. Neurology. 2003;60(11):1756-61.
14. Rajput AH, Fenton ME, Birdi S, Macaulay R, George D, Rozdilsky $\mathrm{B}$, et al. Clinical-pathological study of levodopa complications. Mov Disord. 2002;17(2):289-96.

15. Rascol O, Brooks DJ, Korczyn AD, De Deyn PP, Clarke CE, Lang AE. A five-year study of the incidence of dyskinesia in patients with early Parkinson's disease who were treated with ropinirole or levodopa. 056 Study Group. N Engl J Med. 2000;342(20): 1484-91.

16. Visanji NP, Gomez-Ramirez J, Johnston TH, Pires D, Voon V, Brotchie JM, et al. Pharmacological characterization of psychosis-like behavior in the MPTP-lesioned nonhuman primate model of Parkinson's disease. Mov Disord. 2006;21(11): $1879-91$.

17. Fox SH, Visanji NP, Johnston TH, Gomez-Ramirez J, Voon V, Brotchie JM. Dopamine receptor agonists and levodopa and inducing psychosis-like behavior in the MPTP primate model of Parkinson disease. Arch Neurol. 2006;63(9):1343-4.

18. Scraggs PR, Ridley RM. Behavioural effects of amphetamine in a small primate: relative potencies of the d- and 1-isomers. Psychopharmacology (Berl). 1978;59(3):243-5.

19. Castner SA, Goldman-Rakic PS. Long-lasting psychotomimetic consequences of repeated low-dose amphetamine exposure in rhesus monkeys. Neuropsychopharmacology. 1999;20(1):10-28.

20. Pearce RK, Jackson M, Smith L, Jenner P, Marsden CD. Chronic LDOPA administration induces dyskinesias in the 1-methyl-4phenyl-1,2,3,6-tetrahydropyridine-treated common marmoset (Callithrix Jacchus). Mov Disord. 1995;10(6):731-40.

21. Fox SH, Henry B, Hill M, Crossman A, Brotchie J. Stimulation of cannabinoid receptors reduces levodopa-induced dyskinesia in the MPTP-lesioned nonhuman primate model of Parkinson's disease. Mov Disord. 2002;17(6):1180-7.

22. Jenner P, Rupniak NM, Rose S, Kelly E, Kilpatrick G, Lees A, et al. 1-Methyl-4-phenyl-1,2,3,6-tetrahydropyridine-induced parkinsonism in the common marmoset. Neurosci Lett. 1984;50 (1-3):85-90.

23. Henry B, Fox SH, Crossman AR, Brotchie JM. Mu- and deltaopioid receptor antagonists reduce levodopa-induced dyskinesia in the MPTP-lesioned primate model of Parkinson's disease. Exp Neurol. 2001;171(1):139-46.

24. Segal DS, Weinberger SB, Cahill J, McCunney SJ. Multiple daily amphetamine administration: behavioral and neurochemical alterations. Science. 1980;207(4433):905-7.

25. Robinson TE, Berridge KC. Incentive-sensitization and addiction. Addiction. 2001;96(1):103-14.

26. Schmidt WJ, Beninger RJ. Behavioural sensitization in addiction, schizophrenia, Parkinson's disease and dyskinesia. Neurotox Res. 2006;10(2):161-6.

27. Kimura M. Role of basal ganglia in behavioral learning. Neurosci Res. 1995;22(4):353-8.

28. Knowlton BJ, Mangels JA, Squire LR. A neostriatal habit learning system in humans. Science. 1996;273(5280):1399-402.

29. Schultz W. Dopamine neurons and their role in reward mechanisms. Curr Opin Neurobiol. 1997;7(2):191-7.

30. Costall B, Naylor RJ, Cannon JG, Lee T. Differentiation of the dopamine mechanisms mediating stereotyped behaviour and hyperactivity in the nucleus accumbens and caudate-putamen. $\mathrm{J}$ Pharm Pharmacol. 1977;29(6):337-42.

31. Graybiel AM, Canales JJ, Capper-Loup C. Levodopa-induced dyskinesias and dopamine-dependent stereotypies: a new hypothesis. Trends Neurosci. 2000;2323 Suppl 10:S71-7.

32. Evans AH, Pavese N, Lawrence AD, Tai YF, Appel S, Doder M, et al. Compulsive drug use linked to sensitized ventral striatal dopamine transmission. Ann Neurol. 2006;59(5):852-8.

33. Pierce RC, Kalivas PW. A circuitry model of the expression of behavioral sensitization to amphetamine-like psychostimulants. Brain Res Brain Res Rev. 1997;25(2):192-216.

34. Bezard E, Brotchie JM, Gross CE. Pathophysiology of levodopainduced dyskinesia: potential for new therapies. Nat Rev Neurosci. 2001;2(8):577-88.

35. Zhang X, Lee TH, Davidson C, Lazarus C, Wetsel WC, Ellinwood $\mathrm{EH}$. Reversal of cocaine-induced behavioral sensitization and associated phosphorylation of the NR2B and GluR1 subunits of the NMDA and AMPA receptors. Neuropsychopharmacology. 2007;32(2):377-87. 
36. Smiley PL, Johnson M, Bush L, Gibb JW, Hanson GR. Effects of cocaine on extrapyramidal and limbic dynorphin systems. J Pharmacol Exp Ther. 1990;253(3):938-43.

37. Duty S, Henry B, Crossman AR, Brotchie JM. Topographical organization of opioid peptide precursor gene expression following repeated apomorphine treatment in the 6hydroxydopamine-lesioned rat. Exp Neurol. 1998;150(2): 223-34.

38. Henry B, Duty S, Fox SH, Crossman AR, Brotchie JM. Increased striatal pre-proenkephalin B expression is associated with dyskinesia in Parkinson's disease. Exp Neurol. 2003;183(2): 458-68.
39. Crossman AR. A hypothesis on the pathophysiological mechanisms that underlie levodopa- or dopamine agonist-induced dyskinesia in Parkinson's disease: implications for future strategies in treatment. Mov Disord. 1990;5(2):100-8.

40. Alexander GE, Crutcher MD, DeLong MR. Basal gangliathalamocortical circuits: parallel substrates for motor, oculomotor, "prefrontal" and "limbic" functions. Prog Brain Res. 1990;85:119-46.

41. Robinson TE, Berridge KC. The neural basis of drug craving: an incentive-sensitization theory of addiction. Brain Res Brain Res Rev. 1993;18(3):247-91.

42. Canales JJ, Graybiel AM. Patterns of gene expression and behavior induced by chronic dopamine treatments. Ann Neurol. 2000;47(4 Suppl 1):S53-9. 